\title{
Low-Velocity Impact Craters in Ice and Ice-Saturated Sand With Implications for Martian Crater Count Ages
}

\author{
S. K. Croft \\ Department of Earth and Space Sciences, University of California, Los Angeles, California 90024
}

S. W. KIEFFER

U.S. Geological Survey, Flagstaff, Arizona 86001

T. J. AHRENS

Division of Geological and Planetary Sciences, California Institute of Technology, Pasadena, California 91125

\begin{abstract}
We produced a series of decimeter-sized impact craters in blocks of ice near $0^{\circ} \mathrm{C}$ and $-70^{\circ} \mathrm{C}$ and in ice-saturated sand near $-70^{\circ} \mathrm{C}$ as a preliminary investigation of cratering in materials analogous to those found on Mars and the outer solar system satellites. The projectiles used were standard 0.22 and 0.30 caliber bullets fired at velocities between 0.3 and $1.5 \mathrm{~km} / \mathrm{s}$, with kinetic energies at impact between $10^{9}$ and $4 \times 10^{10}$ ergs. Crater diameters in the ice-saturated sand were $\sim 2$ times larger than craters in the same energy and velocity range in competent blocks of granite, basalt and cement. Craters in ice were $\sim 3$ times larger. If this dependence of crater size on strength persists to large hypervelocity impact craters, then surfaces of geologic units composed of ice or ice-saturated soil would have greater crater count ages than rocky surfaces with identical influx histories. The magnitude of the correction to crater counts required by this strength effect is comparable to the magnitudes of corrections required by variations in impact velocity and surface gravity used in determining relative interplanetary chronologies. The relative sizes of craters in ice and ice-saturated sand imply that the tensile strength of ice-saturated sand is a strong inverse function of temperature. If this is true, then Martian impact crater energy versus diameter scaling may also be a function of latitude.
\end{abstract}

\section{INTRODUCTION}

Impact cratering is recognized as an important process in planetary accretion and in shaping the solid surfaces of planets and satellites in the solar system. Crater counting is frequently used, and is often the only technique available, for estimating both the relative and absolute ages of geologic features on other planets. Most surfaces in the inner solar system consist of rock materials and their weathered products. Consequently, terrestrial small-scale impact and explosion experiments have been performed primarily in rock or soil. However, because of the recognition of the probable dominance of ice and ice-saturated soils, both at and far below the melting point of water over large portions of Mars, the asteroids, and particularly the satellites of the outer solar system, we performed a series of low-velocity impact experiments in ice and ice-saturated sand. The objective of these impact experiments was to provide a preliminary survey of the morphology and kinetic energy-dimensional scaling of craters in icy media compared to impacts at similar kinetic energies and velocities in rock and cohesionless sand.

\section{Experimental Procedure}

The projectiles used were standard 0.22 and 0.30 caliber bullets fired at velocities between 0.3 and $1.5 \mathrm{~km} / \mathrm{s}$. Table 1 gives the ballistic data derived from manufacturer's specifications for the bullets used. Impact kinetic energies at the measured firing ranges $(R)$ of $8-13$ yd $(7-12 \mathrm{~m})$ were interpolated from the ballistic data using the equation

$$
R=\frac{m}{C_{d} A \rho} \log \left(\frac{E_{0}}{E}\right)
$$

Copyright $(1979$ by the American Geophysical Union. where $E_{0}$ is the muzzle energy, $m$ is the bullet mass, $\rho$ is the density of air, $A$ is the cross-sectional area of the bullet, and $C_{d}$ is the coefficient of drag. Equation (1) was derived by integration of Newton's second law using a low-viscosity, ' $\mathrm{V}$ squared' drag force appropriate for bullets [Albertson et al., 1960]. The quantity $m / C_{d} A \rho$ estimated for each bullet is also given in Table 1.

Three types of target blocks were used. They were prepared and characterized as follows:

1. 'Ice-saturated sand' (ISS) blocks consisted of water-saturated sand frozen to approximately $-70^{\circ} \mathrm{C}$. Containers $\sim 27$ $\times 33 \times 16 \mathrm{~cm}$ in size were filled with sand and then water until the sand was covered by a thin water layer. The mixture was slowly stirred to remove air bubbles. The mixture was frozen in the container.

2. 'Supercooled ice' (S-ice) blocks consisted of pure water ice frozen to about $-70^{\circ} \mathrm{C}$, with the same dimensions as the blocks of ice-saturated sand. To prevent the formation of large single crystals or bubbles, these blocks were built up layer by layer, adding first water and then crushed ice until the ice was barely saturated. The water-ice mixture was then frozen, producing blocks having a uniform fine grain phaneritic texture with tiny bubbles $(<0.1 \mathrm{~mm})$ thinly distributed in the interior.

3. 'Temperate ice' (T-ice) blocks consisted of pure water ice near $0^{\circ} \mathrm{C}$ and were prepared in three ways. The first type of temperate ice blocks used were commercially produced and maintained in a freezer at a temperature of $\sim 28^{\circ} \mathrm{F}\left(-2.2^{\circ} \mathrm{C}\right)$. These blocks were $\sim 36 \times 20 \times 20 \mathrm{~cm}$ in size. The commercial method of freezing produced a roughly tabular amorphous core ('cloudy zone') imbedded in a matrix of elongated rodlike crystals $(\sim 0.5-1 \mathrm{~cm}$ long and $0.2-0.3 \mathrm{~cm}$ thick) oriented perpendicular to the face of the tabular cloudy zone. This pro- 
TABLE 1. Bullet Ballistic Data

\begin{tabular}{|c|c|c|c|c|c|c|}
\hline \multirow[b]{2}{*}{ Bullet } & \multirow[b]{2}{*}{ Mass, $\mathbf{g}$} & \multicolumn{2}{|c|}{ Velocity, km/s } & \multicolumn{2}{|c|}{ Energy, ergs } & \multirow[b]{2}{*}{$\mathrm{m} / C_{d \rho} \rho A, \mathrm{~cm}$} \\
\hline & & Muzzle & $100 \mathrm{yd}^{\star}$ & Muzzle & $100 \mathrm{yd}^{*}$ & \\
\hline 22 Short $(22 S) \dagger$ & 1.88 & 0.334 & 0.275 & $1.04 E 9 \ddagger$ & $7.05 E 8$ & $5.36 E 4$ \\
\hline 22 Long (22L) $\dagger$ & 1.88 & 0.378 & 0.294 & $1.34 E 9^{\circ}$ & $8.13 E 8$ & $4.20 E 4$ \\
\hline 22 Long Rifle (22LR) $\dagger$ & 2.59 & 0.383 & 0.310 & $1.90 E 9$ & $1.25 E 9$ & $5.01 E 4$ \\
\hline 22 Hornet $(22 \mathrm{H}) \dagger$ & 3.24 & 1.25 & NA & $2.54 E 10$ & NA & $\begin{array}{l}4.86 E 4 \\
\quad \text { (estimated) }\end{array}$ \\
\hline $\begin{array}{l}\text { 30-06SPRG Accelerator } \\
\text { (SPRG) } \dagger\end{array}$ & 3.56 & 1.48 & NA & $3.88 E 10$ & NA & $\begin{array}{l}4.86 E 4 \\
\text { (estimated) }\end{array}$ \\
\hline 30-06PSP (PSP) $\dagger$ & 8.10 & 0.975 & 0.856 & $3.85 E 10$ & $2.97 E 10$ & $8.11 E 4$ \\
\hline
\end{tabular}

NA is not available.

* 1 yd $=0.91 \mathrm{~m}$

†Abbreviation used in Table 2.

$\ddagger$ Read $1.04 E 9$ as $1.04 \times 10^{9}$.

vided for highly anisotropic material properties whose effects on the craters are noted below.

The second temperate ice blocks ('pressed blocks') were prepared by compressing crushed ice in a pressure vessel until fusion. This produced a uniform but porphyritic texture with many millimeter-sized bubbles. These blocks were cylinders with diameters and lengths of $\sim 20 \mathrm{~cm}$.

The third temperate ice ('pot') blocks were prepared by saturating a container filled with crushed ice and then freezing. This method produced nonuniform porphyritic textures with occasional large air pockets (which did not affect the results reported below, as we discarded samples where the bullet obviously hit an air pocket). These blocks were cylinders $\sim 25 \mathrm{~cm}$ in diameter and $\sim 15 \mathrm{~cm}$ long.

The internal temperatures of the blocks were made initially constant by prolonged residence in monitored refrigerators. The volumes of the refrigerators available severely limited the maximum practical size of the target blocks. The blocks remained in the refrigerators until transferred to insulated boxes for immediate transport to the firing range. Temperatures inside the insulated containers were monitored. On the basis of (1) the time between removal from the refrigerators until use at the firing range (a few hours), (2) the air temperatures inside the insulated boxes at the time of target use $\left(\sim 0^{\circ} \mathrm{C}\right.$ for the temperate ice blocks and $-14^{\circ} \mathrm{C}$ for the ice-saturated sand and supercooled ice blocks), (3) the thermal properties of ice, and (4) the parameterized temperature history calculations of Schneider [1974], it is estimated that the surface temperatures of the supercooled ice and ice-saturated sand blocks had risen between $5^{\circ}$ and $10^{\circ} \mathrm{C}$, while those of the temperature ice blocks had risen a few tenths of a degree. The temperature gradient near the surface of the supercooled ice and ice-saturated sand blocks is estimated to have been $\sim 0.5^{\circ} \mathrm{C} / \mathrm{cm}$ from Schneider's [1974] calculations. Edges and corners of the blocks would have been a few degrees warmer, but as the craters were formed in the approximate centers of the block faces, the influence of temperature edge effects on crater formation was deemed negligible.

At time of use, target blocks were removed from the insulated boxes and the containers in which they were frozen and were immediately buried in an embankment of soil with one exposed vertical face into which the bullet was fired. Figure 1 shows the placement and orientation of a block of ice-saturated sand in a sand embankment. The faces of the supercooled ice and ice-saturated sand blocks used as targets. were the $27 \times 33 \mathrm{~cm}$ bottom faces, which had smooth surfaces. The target faces of the pot and pressed blocks were the flat end faces, which had vertical relief of $\leqslant 3 \mathrm{~mm}$. All faces of the commercial ice blocks were used; these surfaces were also smooth. Bullet name, target type, range, and crater depth and diameter were recorded for each shot. Those data are grouped according to target composition and listed by shot number in order of increasing impact energy in Table 2. Crater 5 is shown in Figure 1. Depths were measured from the original target surface. Diameters are averages of the largest and smallest diameters of each crater.

\section{RESULTS}

With the notable exception of craters formed in the commercial ice blocks, the craters were hemielliptical cups in cross section. The subsurface fracture systems were both concentric and radial in pattern similar to those found around $\sim 5-\mathrm{cm}-\mathrm{di}-$ ameter impact craters in Arkansas Novaculite by Curran et al. [1977]. Radial fractures were dominant in craters in ice, while fine concentric fractures predominated in the ice-saturated sand craters. Visible fracturing was concentrated near the impact site and near the rear face of the target block. Shots 4 (Sice) and 9 (ISS), which were fired into blocks which each already had a $5-\mathrm{cm}$ crater in them (whose visible fracture zones were small in comparison to the block size), completely shattered the blocks. Identical shots ( 3 in S-ice and 10 in ISS) into undamaged blocks produced measurable craters and only split the blocks. It is concluded that the craters produced extensive, less obvious interior failure beyond the visible fracture systems.

The upper limit of usable impact energies was set by the target block size and composition. For blocks in the size range used, the upper energy limit for ice blocks is $\sim 3 \times 10^{10} \mathrm{ergs}$, because shot 16 at $3.7 \times 10^{10}$ ergs completely destroyed the target block, while shot 3 , at $2.5 \times 10^{10}$ ergs, did not. The upper limit for the ice-saturated sand blocks appears to be near $5 \times 10^{10}$ ergs. In order to gain as large a range in energy as possible for scaling analysis, craters were produced with crater/target block dimension ratios ranging from $\sim 0.1$ to 0.7 . There are several possible effects on the expected crater dimensions due to the large change of crater size relative to the target size. Gehring [1970 $b$ ] analyzed the depth of penetration of a projectile of given mass and energy as a function of target thickness in metals. He found very little change in expected crater dimensions until the depth of the expected crater was $\geqslant 0.5$ the target thickness, beyond which the diameter narrowed slightly [Gehring, 1970a] and the depth increased rapidly toward penetration. The sudden increase in crater depth is due to spallation and failure of the target's rear face caused 


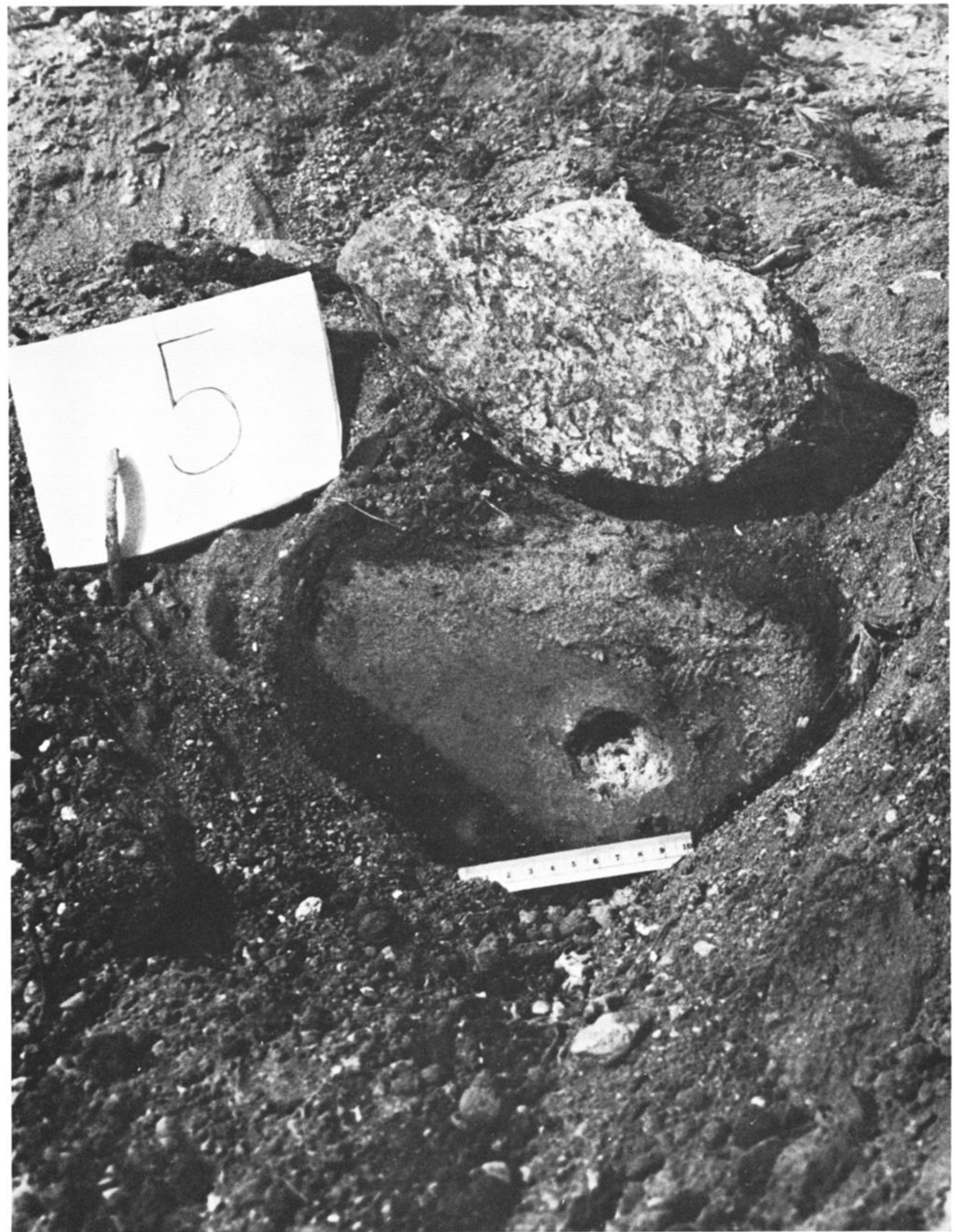

Fig. 1. Crater 5 in ice-saturated sand showing an example of the craters discussed in this report and the target arrangement of ice-saturated sand block bunkered by sand with one vertical face exposed. Note the relatively large depth/diameter ratio ( $\sim 0.4$ compared to typical hard rock values of $\sim 0.2)$ and the system of cracks surrounding the crater to approximately one crater radius beyond the slightly raised rim. White scale bar is $\sim 10.5 \mathrm{~cm}$ long. 
TABLE 2. Crater Data Summary

\begin{tabular}{|c|c|c|c|c|c|c|}
\hline Shot & Bullet* & $\begin{array}{c}\text { Range, } \\
\text { yd } \dagger\end{array}$ & $\begin{array}{l}\text { Energy } \\
E_{v}, \text { ergs }\end{array}$ & $\begin{array}{c}\text { Diameter } \\
D, \mathrm{~cm}\end{array}$ & $\begin{array}{l}\text { Depth } \\
d, \mathrm{~cm}\end{array}$ & Notes \\
\hline \multicolumn{7}{|c|}{ S-Ice } \\
\hline 1 & $22 \mathrm{~S}$ & 13.3 & $1.00 E 9 \ddagger$ & $4.5 \pm 0.5$ & 2.6 & \\
\hline 2 & 22L & 13.3 & $1.26 E 9$ & $7 \pm 3$ & 2.5 & $\begin{array}{l}\text { double crater, } D_{1}=4 \mathrm{~cm} \text {, } \\
D_{0}=10 \mathrm{~cm}\end{array}$ \\
\hline 3 & $22 \mathrm{H}$ & 13.3 & $2.48 E 10$ & $\sim 23$ & $\sim 13$ & block split \\
\hline 4 & $22 \mathrm{H}$ & 13.3 & $2.48 E 10$ & $\cdots$ & $\cdots$ & block destroyed, prefractured by 1 \\
\hline \multicolumn{7}{|c|}{ Ice-Saturated Sand } \\
\hline 5 & $22 \mathrm{~S}$ & 10 & $1.01 E 9$ & $4.25 \pm 0.25$ & 1.8 & \\
\hline 6 & $22 \mathrm{~L}$ & 10 & $1.82 E 9$ & $4.9 \pm 0.1$ & 2.0 & in same block as 5 \\
\hline 7 & $22 \mathrm{~L}$ & 10 & $1.82 E 9$ & 5.0 & 1.8 & \\
\hline 8 & $22 \mathrm{H}$ & 13.3 & $2.48 E 10$ & 12 & 5.0 & block split \\
\hline 9 & PSP & 10 & $3.69 E 10$ & $\ldots$ & ... & block destroyed, prefractured by 7 \\
\hline 10 & SPRG & 10 & $3.70 E 10$ & -16 & $\sim 5.6$ & block split \\
\hline \multicolumn{7}{|c|}{ T-Ice (Commercial) } \\
\hline 11 & $22 S$ & 10 & $1.01 E 9$ & 6 & 0.8 & into cloudy zone \\
\hline 12 & $22 S$ & 10 & $1.01 E 9$ & 6.5 & 2.6 & $\begin{array}{l}\text { perpendicular to grain axes, } \\
\text { square crater }\end{array}$ \\
\hline 13 & $22 S$ & 10 & $1.01 E 9$ & 6.5 & 3.0 & $\begin{array}{l}\text { perpendicular to grain axes, } \\
\text { square crater }\end{array}$ \\
\hline 14 & $22 \mathrm{~S}$ & 10 & $1.01 E 9$ & 4.5 & 10.9 & $\begin{array}{l}\text { parallel to grain axes, } \\
\text { conical crater }\end{array}$ \\
\hline 15 & 22LR & 10 & $1.82 E 9$ & $4.9 \pm 0.5$ & 8.5 & $\begin{array}{l}\text { parallel to grain axes, conical } \\
\text { crater }\end{array}$ \\
\hline 16 & SPRG & 10 & $3.70 E 10$ & $\cdots$ & $\cdots$ & block destroyed \\
\hline \multicolumn{7}{|c|}{ T-Ice (Pots) } \\
\hline 17 & $22 S$ & 9.2 & $1.01 E 9$ & $6.5 \pm 0.5$ & 3 & $\begin{array}{l}\text { pot } 6 \text {, large single crystals } \\
\text { in block }\end{array}$ \\
\hline 18 & 22LR & 10.8 & $1.81 E 9$ & $3.8 \pm 0.3$ & 1.5 & pot 2 , wrong or faulty bullett?? \\
\hline \multicolumn{7}{|c|}{ T-Ice (Pressed Blocks) } \\
\hline 19 & $22 \mathrm{~S}$ & 8.3 & $1.02 E 9$ & 5 & 3 & upper quadrant spalled off \\
\hline 20 & 22LR & 10.8 & $1.81 E 9$ & $\sim 10$ & $\sim 5.5$ & upper right half spalled off \\
\hline
\end{tabular}

*See Table 1 for full designation.

$+1 \mathrm{yd}=0.91 \mathrm{~m}$.

$\ddagger$ Read $1.00 E 9$ as $1.00 \times 10^{9}$.

by the strong rarefaction generated by reflection of the primary shock off of the free rear face. By burying the targets in a medium with a density comparable to the target density, shock reflection and spallation are reduced, increasing the effective target thickness. Crater 3 , with a crater depth/block thickness ratio of $\sim 0.7$, is the only crater large enough to have possibly had its dimensions significantly altered by near per-

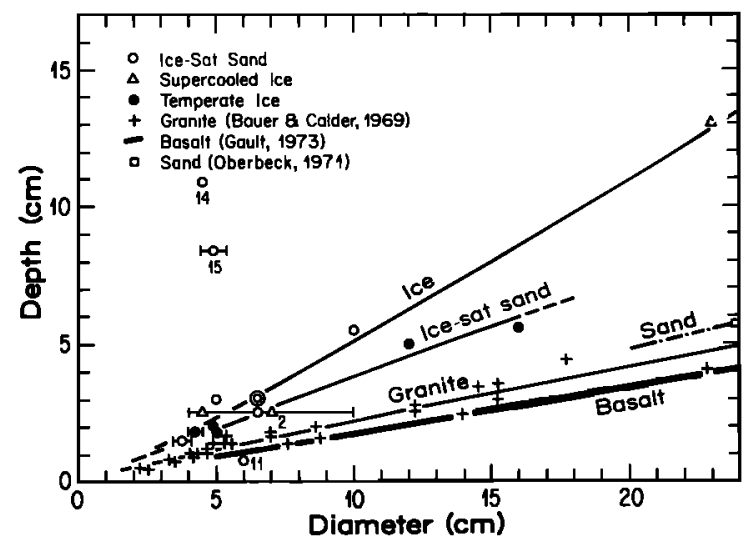

Fig. 2. Depth/diameter relation for the craters in this study and for low-velocity impacts in granite and hypervelocity impacts in sand and basalt. The numbers in this figure refer to crater numbers given in Table 2 and designate four data points considered anomalous as discussed in the text. foration. However, as seen in Figure 2 and discussed below, the depth/diameter ratio of crater 3 , which would be anomalously large had near performation occurred, is similar to that of the other ice craters. Thus any effects of varying target thickness relative to crater size are deemed small for these experiments.

Burial of the target was also intended to reduce lateral spallation. However, as is seen in Figure 1, the loose nature of the sand prevented effective enclosure of the upper forward portions of the target. As a result, large sections were spalled off of the upper face of the blocks containing craters 19 and 20 (which were otherwise normal). The three largest craters $(3,8$, and 10) completely split their respective target blocks owing to insufficient lateral containment. Because the energy required to generate fractures beyond the true crater is small in comparison to the energy needed to crush and eject material from the crater [Gault et al., 1975; Kutter and Fairhurst, 1971], the effects of large-scale target splitting on crater dimensions are also considered small.

Crater shapes in the highly anisotropic commercial ice blocks depended on the orientation of ice crystals at the face in which the crater was formed. Craters 14 and 15 were formed in the face with the long axes of the ice grains parallel to the projectile velocity. The craters are abnormally deep and conical in shape in comparison to those in the polycrystalline anisotropic ice blocks. Ejecta consisted of large rodlike segments of individual crystals and a relatively undamaged 'plug' thrown several feet in front of the target. The undamaged na- 


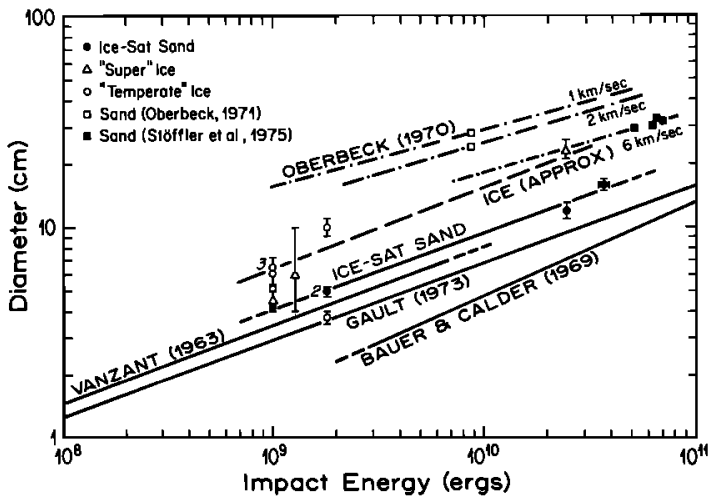

Fig. 3. Dependence of crater diameter on impact energy for ice (dashed line) and ice-saturated sand (uppermost solid line) craters compared to craters in the same energy and velocity range in rock (lower solid lines) and sand (dot-dashed lines). The numbers by certain symbols in this figure refer to the number of superposed impacts represented by the single symbol.

ture of the plug is consistent with observations and calculations by Curran et al. [1977] for similar low-velocity impacts. Although it is possible that vapor formation ejected the plug, we do not believe it likely at these low velocities and suspect that elastic forces ejected the plug. At higher velocities, both plug and individual crystals are fragmented.

Craters 12 and 13 were formed in commercial block faces with the long axes of the ice grains oriented perpendicular to the projectile velocity, and are roughly inverted pyramids in shape. Two faces of the 'pyramid' consist of the broken ends of grains, while the other two sides are defined by the sides of the ice grains. Crater 11 was formed in the amorphous cloudy zone and has a typical hemispherical profile. These craters in the commercial ice blocks illustrate the importance of grain size and orientation in small-scale, low-velocity impacts.

For all craters, projectile deformation was similar to that found in other studies. In the low-velocity permafrost craters the bullet was recovered in the bottom of the crater or in front of the target. Bullets turned 'inside out' at velocities of $\geq 300$ $\mathrm{m} / \mathrm{s}$, in accord with observations by Culp and Hooper [1961]. At velocities of $\geqslant 1 \mathrm{~km} / \mathrm{s}$ the bullets disintegrated to a fine gray powder in accord with observations of end products of missile components in impacts in alluvium [Moore, 1976].

Figure 2 shows the quantitative relation between depth and diameter for the craters formed in these experiments. Included for comparison are steel and tungsten carbide ball bearing impacts in Disraeli Light granite by Bauer and Calder [1969] in the same velocity and energy range as our impacts, low-veloc- ity to hypervelocity impacts in sand (Oberbeck [1971], apparent crater dimensions), and the mean curve of Gault's [1973] hypervelocity impacts in basalt and granite. The anomalous depths of craters 14 and 15 in the commercially prepared ice blocks are immediately apparent. Crater 11 appears abnormally shallow because the depth measured was to the top of debris left in the crater rather than to the bottom of the debris layer as was done for the other craters. Crater 2 had a welldefined depth but consisted of a double crater with an inner deep portion $\sim 4 \mathrm{~cm}$ across and an outer shallow spall zone $\sim 10 \mathrm{~cm}$ across. This crater shape, unique in this set of experiments, is probably the result of inhomogeneities in the target block. These four craters were ignored in least-squares fitting of the data. The lines labeled ice and ice-sat. sand are leastsquare fits to the data. From the figure it is seen that the depth/diameter ratios of craters in rock are $\sim 0.2$, of craters in sand are $\sim 0.25$, of craters in ice-saturated sand are $\sim 0.35$, and of craters in ice are nearly 0.5 . Thus at least small-scale craters in ice are nearly hemispherical in shape. Interestingly, this corresponds to the shape suggested as necessary by Ostro and Pettengill [1978] to account for the unexpected polarization properties of radar returns from Europe, Ganymede, and Callisto, whose crusts apparently are largely composed of ice.

Figure 3 shows the corresponding plot of crater diameter as a function of impact energy. In addition to the data of Gault [1973] and Bauer and Calder [1969] an energy-diameter curve derived from the low-velocity steel bullet impacts of Vanzant [1963] into cement are shown, as well as additional apparent sand crater data from Oberbeck [1970] and Stöffler et al. [1975]. The uppermost solid line is a least-squares fit to the ice-saturated sand data. The estimated energy-diameter relation for the ice craters (dashed line in Figure 3) appears to have a logarithmic slope equal to or slightly larger than the ice-saturated sand slope, but the data are insufficient for a reliable fit. Craters 14 and 15 are omitted from this figure because their dimensions were completely altered by the anisotropy of the commercial ice block face in which they were formed. Crater 18 has a normal depth/diameter ratio but is less than half its expected diameter in Figure 3. The small size could be the result of a faulty bullet. Comparison of the curves of Gault [1973] and Bauer and Calder [1969] between Figures 2 and 3 shows that at a given energy, Gault's hypervelocity craters are somewhat larger in diameter but have about the same depth as Bauer and Calder's low-velocity craters. This could be due to either the different velocities used or peculiarities of the material properties of the targets. The kinetic energy-diameter relations of the sand craters have noticeably different logarithmic slopes that are weak functions of

TABLE 3. Empirical Energy-Diameter Relations (Shown in Figure 3)

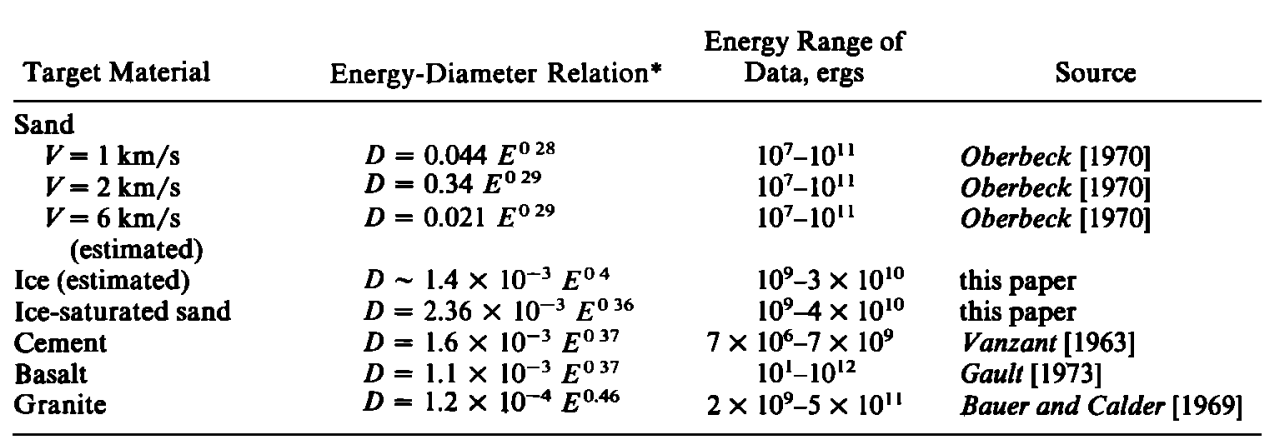

$D$ is in centimeters, and $E$ is in ergs. 
TABLE 4. Rock Tensile Strengths

\begin{tabular}{lcll}
\hline \multicolumn{1}{c}{ Material } & $\sigma_{t}$, bars & Type Test & \multicolumn{1}{c}{ Reference } \\
\hline Granite & 75 & static & Maurer and Rinehart [1960] \\
Pink & 68 & static & Rinehart $[1965]$ \\
& 388 & dynamic & Rinehart [1965] \\
Charcoal gray & $140 \pm 8$ & static & Reichmuth $[1968]$ \\
& $179 \pm 35$ & dynamic & Reichmuth $[1968]$ \\
Cheyenne Mt. & $88 \pm 18$ & static & Reichmuth $[1968]$ \\
Bohus & $80 \pm 10$ & static & Wijk et al. $[1978]$ \\
Westerly & $1140 \pm 110$ & dynamic & Cohn and Ahrens $[1979]$ \\
Basalt & & & \\
Buckboard Mesa & 184 & dynamic & Curran et al. $[1977]$ \\
Ralston & $1168 \pm 160$ & dynamic & Cohn and Ahrens [1979] \\
Cement & $30-60$ & static & LaLonde and Janes [1961] \\
\hline
\end{tabular}

velocity [Oberbeck, 1970]. The energy-diameter relations shown in Figure 3 are given in numerical form in Table 3.

Two significant observations can be made from these data. First, at a given energy, craters in ice-saturated sand are $\sim 2$ times larger, and craters in ice are $\sim 3$ times larger in diameter than craters in rock. The increase in crater diameter at a given energy from rock to ice-saturated sand to ice is of the same order as the increase in the depth/diameter ratio, implying a dependence of both size and morphometry on material properties. Second, the logarithmic slopes of the low-velocity and hypervelocity impacts are similar to the slope for the ice-saturated sand. Because crater dimensions are obtained late in the impact event and at relatively low pressures, we believe that the similarity of slopes implies that similar mechanisms of material failure operate in the late stages of both low-velocity and hypervelocity impacts.

It has been postulated that the final size of craters in competent media in this diameter range is determined by the dynamic tensile strength of the material [Curran et al., 1977; J. S. Rinehart, personal communication, 1978]. Near the point of impact the peak shock stress greatly exceeds the material's dynamic compressive strength $\sigma_{c}$, thus crushing target materials which are subsequently ejected. At greater distances the compressive stresses fall below $\sigma_{c}$, but excavation continues because the tensile stresses in the rarefaction still exceed the much smaller dynamic tensile strength $\sigma_{r}$ of the material. En-

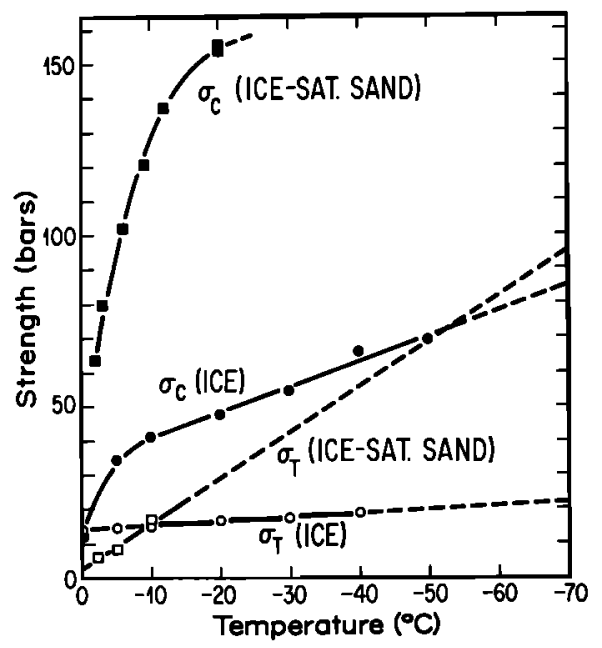

Fig. 4. Variation of crushing strength $\sigma_{c}$ and tensile strength $\sigma_{r}$ of ice [from Butkovich, 1959] and ice-saturated sand [from Tsytovich, 1975] with temperature. Dashed lines are extrapolations. Data for $\sigma_{t}$ (ice-sat. sand) are particularly restricted in temperature range. largement of the crater continues by tensile failure and spalling until radial tensile stresses fall below $\sigma_{i}$. Cracks often extend far beyond the crater into the target because of the strong tensile tangential stresses [Kutter and Fairhurst, 1971]. Crushing early in the impact event and spalling via tensile failure late in the event account for both the distribution of ejecta particle sizes and the visual appearance of craters in hard rock. Both low- [Bauer and Calder, 1969] and high- [Moore et al., 1962] velocity craters have similar inner zones of highly fractured and crushed material surrounded by a larger zone of radial and spall fractures. The ejecta in both high- and lowvelocity impacts consists of fine crushed material from the inner crater zone grading into large spall fragments from the outer zone. Crater edges are often irregular. In the ice and small ice-saturated sand craters the outer spall zone was not as obvious, and the largest ejected particle sizes were relatively smaller than the largest hard rock fragments in comparison to the crater diameter. Only the large ice-saturated sand craters exhibited a prominent spall zone and large spall fragments. This implies that crushing and spalling occur in ice and hard rock craters, though perhaps in differing relative importance. The edges of the ice craters were also quite regular.

The tensile strengths of sand $\left(\sigma_{t}=0\right)$, ice, ice-saturated sand, cement, basalt, and granite show an inverse correlation with the crater size progression observed. The tensile strengths of the rocks are given in Table 4. They range from a few tens to a few hundreds of bars. The tensile strengths of ice and icesaturated sand are functions of temperature as shown in Figure 4. For ice, $\sigma$, shows a slight increase with decreasing temperature. In accord with the correlation of tensile strength with crater size we would expect craters in supercooled ice to be marginally smaller than craters in temperate ice. There is some indication in Figure 3 that this is the case, but more data must be obtained to be sure. For ice-saturated sand, $\sigma_{r}$ is actually smaller than $\sigma_{t}$ for ice near the melting point, but the available data imply a strong increase in $\sigma_{t}$ as the temperature decreases. Comparison with $\sigma$, for cement and granite implies that to obtain craters in ice-saturated sand in the size range observed requires $\sigma_{t}$ (ISS) near $-70^{\circ} \mathrm{C}$ to be somewhere between 20 and 50 bars. Again, more data need to be obtained to be sure, but the crater data appear to confirm a strong temperature dependence of $\sigma_{t}$ (ISS) on temperature.

A more quantitative treatment is prevented at this time by the lack of direct $\sigma$, measurements of the cratered material, forcing comparisons to be made between strengths cited in the literature that may or may not be appropriate. There are also inconsistencies in the measured values of dynamic $\sigma_{t}$, with some investigators reporting values similar to static values and 
others giving dynamic measurements much larger than static values.

\section{Discussion}

The validity of scaling results from typical lab-sized craters tens of centimeters in diameter to craters exceeding hundreds of meters in diameter is generally somewhat dubious. In particular, crater dimensions in competent targets at the scale of decimeters are determined by strength properties, whereas gravity dominates cratering efficiency at diameters larger than a few kilometers, with an ill-defined transition in between [Gault et al., 1975]. The extent of the influence of strength properties in cratering at large scales is brought into further question by the recognition that most natural rock and soil units have faults, joints, and impact or weathering fractures that decrease the effective tensile strength of the unit with increasing crater size. Moore [1976] noted that the ejected mass versus impact energy relation for missile impacts in soil intersect the extrapolations of similar relations for craters in sand [Oberbeck, 1970] and rock [Gault, 1973] at energies around $10^{15}-10^{16}$ ergs, corresponding to diameters of 5-10 m (the trend toward convergence is apparent in Figure 3). Taken by itself, this implies a disappearance of strength effects by energies of $\sim 10^{16}$ ergs. Gault [1973], in limiting the valid range of extrapolation of his empirical scaling equations for craters in basalt, observed that during surface explosions in rock at energies of $10^{15}-10^{16}$ ergs, large spall plates that would have been ejected at smaller diameters were only slightly moved before settling, reducing the diameter of the final crater. Certainly, Sailor Hat B, a $2 \times 10^{19}$ erg hemispherical high-explosive (HE) surface burst on basalt producing an apparent crater diameter of $\sim 48 \mathrm{~m}$ [Vortman, 1968], is far smaller than the $\sim 150-\mathrm{m}$ diameter predicted by simple extrapolation of Gault's relation given in Table 3 (ignoring effects of depth of burst; rock porosity, etc.). This implies that gravity begins to affect crater dimensions significantly at diameters around 5$10 \mathrm{~m}$.

There is evidence, however, that strength properties continue to measurably affect crater dimensions at diameters much larger than $10 \mathrm{~m}$. Crater dimensions and empirical scaling relations for surface HE bursts given by Vortman [1968] indicate that at equal energies, craters in rock continue to be $\sim 25 \%$ smaller than craters in dry soil up through the largest energy $\left(\sim 10^{17} \mathrm{ergs}\right)$ for which data in both media are available. Similar strength-induced differences are noted in explosion craters with large scaled depths-of-burst to energies of $\geq 10^{21}$ ergs $(D \geq 100 \mathrm{~m}$ ), the upper limit of available data [Toman, 1970; Cooper, 1977]. Thus strength effects persist to energies much larger than Moore's [1976] extrapolated intersection, implying changes in the empirical scaling laws at energies of $\leq 10^{15}$ ergs. Schultz and Spencer [1979] reported 23 times as many craters in the 10 - to $100-\mathrm{m}$ diameter range on ejecta deposits than on presumably contemporaneous smooth ponded melt at King Crater. Schultz suggested that the difference in crater density may be attributable to strength differences between the incompetent ejecta and the competent ponded melt. The diameter-frequency distributions for craters on the two surface units converge toward an extrapolated intercept near $3 \mathrm{~km}$. Schultz interpreted this as the size range where gravity becomes significant in relation to strength in determining crater dimensions. Dence et al. [1977] note that the transition from simple to complex craters on the earth occurs at $\sim 1.5-2 \mathrm{~km}$ in sedimentary rock and at $\sim 4 \mathrm{~km}$ in crystalline rock, implying the transition to be a function only of energy and target material properties.

These observations suggest that the diameter range of craters for which strength effects are nonnegligible but of diminishing importance in determining crater dimensions extends from $\sim 10 \mathrm{~m}$, where gravity effects first become noticeable, to several kilometers. The diameter range of craters typically used in determining the relative and absolute ages of geologic units on the moon [e.g., Young, 1975; Neukum and König, 1976] and Mars [e.g., Masursky et al., 1977] extends from 10 $m$ to $\sim 10 \mathrm{~km}$. These two ranges overlap. Further, it has been postulated that Mars is or was totally or partially covered by a thick layer of ice-saturated soil. Consequently, the differences in crater diameter between equal energy impacts in icy and rocky media presented in this report may have implications for Martian crater count analyses:

1. The crater count ages of competent icy or ice-saturated soil geologic units that are not in cratering equilibrium for the range of crater diameters used in age determinations will be greater than the crater count ages of competent rock units experiencing identical infall histories. This is best demonstrated by relating the flux of impacting objects, $N$ (number of impactors per unit area per unit time in a prescribed impactor radius (r) interval), with the primary crater production rate $F$ (number of craters formed per unit area per unit time in a prescribed crater diameter interval) in a manner similar to that of Gault [1970]. The cumulative radius-flux relation of a population of impactors is usually expressed in the form [Hartmann, 1969; Gault, 1970]

$$
N=k_{1} r^{-\beta}
$$

where $k_{1}$ and $\beta$ are positive constants. Upon impact at velocity $V$ an impactor will have kinetic energy $E$ :

$$
E \cong 2 / 3 \pi \rho V^{2} r^{3}
$$

where $\rho$ is the bulk density of the impactor. The diameter $D$ of the crater generated by this impact is given by a power law scaling relation

$$
D=k_{2} E^{1 / \alpha}
$$

where $k_{2}$ is a constant for a given planet and lithology and $\alpha$ is the scaling coefficient with a value [Gault et al., 1975] between 3 (strength dominated) and 4 (gravity dominated). Equations (2), (3), and (4) may be combined to eliminate $E$ and $r$ and thereby convert the cratering flux into a crater production rate as a function of crater diameter:

$$
F=k V^{2 / 3} k_{2}^{\alpha \beta / 3} D^{-\alpha \beta / 3}
$$

where all other constants have been absorbed into $k$.

Hartmann [1977] calculated correction factors that can be used to predict the crater production rate $F$, on any planet relative to a standard rate $F_{s}$ :

$$
F_{i}=X Y Z F_{s}
$$

where $X$ is the ratio of the calculated flux of a specific family of impactors onto the planet under investigation to the calculated flux of that family on the standard planet, $Y$ corrects for the difference in mean impact velocity for the family on the two planets, and $Z$ corrects for the difference in surface gravity. Hartmann's values of $Y$ and $Z$ range from $\sim 0.5$ to 2 for 
the terrestrial planets and somewhat higher for satellites in the outer solar system. A strength correction factor $S$ may be defined analogously to $Y$ and $Z$ by noting that comparison of (4) with the scaling laws given in Table 3 indicates that the increase in crater diameter with decreasing material strength is reflected primarily by an increase in $k_{2}$. Therefore $S$ may be defined from (5) and (6) holding $X, Y, Z, D$, and $V$ constant:

$$
S \equiv F_{i} / F_{s}=\left[k_{2}(i) / k_{2}(s)\right]^{\alpha \beta / 3}
$$

where $k_{2}(i)$ refers to the surface being investigated and $k_{2}(s)$ refers to a known standard surface. (The values of $k_{2}$ can be compared directly only if the values of $\alpha$ are similar. When differences in $\alpha$ are large, $k_{2}(i) / k_{2}(s)$ becomes the ratio of crater diameters in different media within a small energy interval and will be a function of energy.) Hartmann's suggested standard surface is an average of dated lunar maria, which are layered targets with varying depths of regolith overlying bedrock [Quaide and Oberbeck, 1968].

The approximate mass range of objects with impact velocities of $10-30 \mathrm{~km} / \mathrm{s}$ that produce craters between 0.1 and $10 \mathrm{~km}$ in diameter is $\sim 10^{8}-10^{14} \mathrm{~g}$, based on a scaling relation given by Gault [1974]. If the diameter increments in (5) are logarithmic [Hartmann, 1969], then the value of $\beta$ for these particles is $\sim 3$ [Gault, 1970]. Substitution of this value of $\beta$ into (5) gives absolute values between 3 and 4 for the exponents of $k_{2}$ and $D$. Because of the decrease in the importance of strength in craters larger than a few meters, the diameter ratio of craters in ice-saturated soil to those in rock produced by identical impacts $\left(k_{2}\right.$ (ISS) $/ k_{2}$ (rock)) will probably be much smaller than the factor of 2 implied by Figure 3 . However, even if the increase in diameter (and thus in $k_{2}$ ) were only $25 \%$, the typical variation for explosion craters in different media on the earth, the exponent of $k_{2}$ (ISS) $/ k_{2}$ (rock) is so large that the primary crater production rate in ice-saturated soils at a given diameter would be $\sim 1.7-2$ times larger than the production rate generated in rock by the same impact flux. Thus $S$ can be as large as $Y$ or $Z$, with decreasing strength working in the same direction as decreasing gravity and increasing impact velocity. It is beyond the scope of this report to detail the correspondence between the production rate and observed crater densities (which can be quite complex; e.g., see discussion by Schultz et al. [1977]), but it is probably reasonable to conclude that the larger production rate for a given flux on ice-saturated soil surfaces will produce higher crater frequencies and larger crater count ages than found for rock surfaces of the same absolute age and subjected to the same flux.

Most of the examples of differing crater diameters for equal energy impacts or explosions cited so far have been the result of the contrasting cratering properties of competent and incompetent geologic units of similar rocky composition. Our cratering experiments indicate the possibility of significant variations in crater dimensions due to differences in strength of competent materials of different composition. The magnitude of the effect of contrasting cratering properties of regolith and bedrock on crater diameter-frequency distributions has been discussed previously for the lunar case [e.g., Chapman et al., 1970; Young, 1975; Schultz et al., 1977]. It might be expected that craters in incompetent media would always be larger than those of equal energy in weak competent media because incompetent materials represent the limiting case of zero tensile strength. However, the logarithmic slopes of the energy-diameter relations for the sand craters shown in Figure 3 are significantly smaller than those of the competent targets.
There is also a marked inverse correlation between crater size and impact velocity at a given energy such that the sand craters formed by projectiles traveling $\sim 6 \mathrm{~km} / \mathrm{s}$ [Stöffler $e t$ al., 1975] lie near the extrapolation of our approximate low-velocity energy-diameter relation for ice. The depth/diameter ratios of the sand craters are similar to the ratios for craters in granite and basalt (Figure 2) and are much smaller than expected on the basis of strength properties alone. The anomalous logarithmic slopes, depth/diameter ratios, and the porous, cohesionless nature of sand suggest that the mechanisms dominant in the formation of craters in sand are different from those that dominate cratering in competent materials. Oberbeck [1970] suggests that at low impact velocities the major constraint on crater size is the energy required to lift material out of the crater against gravity, whereas at higher impact velocities the higher shock pressures increase the effective shear strength of sand, changing the relative importance of strength to gravity in cratering processes. Oberbeck suggests that the change of relative importance between strength and gravity is indicated by the change of the scaling coefficient from $\sim 3.8$ at $V=0.5 \mathrm{~km} / \mathrm{s}$ to $\sim 3.4$ at $V=5 \mathrm{~km} / \mathrm{s}$. In contrast, the diameter-energy scaling coefficient of high-velocity missile impacts in sand, colluvium, alluvium, and soil in the energy range of $10^{15}-10^{16}$ ergs found by Moore [1976] is $\sim 2.4$, a very different result. Consequently, the size of equal energy craters in cohesionless rock materials relative to competent icy materials at energies above $10^{\prime \prime}$ ergs is very difficult to predict on the basis of currently available data.

The presence of water in both competent [Butkovich, 1971; Burton et al., 1975] and incompetent [Moore, 1976] target materials can enlarge crater diameters 2-4 times over the corresponding dry target diameters. Boyce and Roddy [1978] have discussed the possible effects of such enlargements on Martian crater count ages, with conclusions similar to ours. Crater enlargement occurs because (1) water vapor is essentially an uncondensable gas compared to rock vapor, greatly enhancing gas acceleration of particles [Butkovich, 1971] and (2) material shear strength decreases with increasing water content [Burton et al., 1975]. The minimum shock pressure that causes water to begin vaporization upon release is $\sim 50$ kbar [Butkovich, 1971]. However, the maximum pressures at the point of impact for our craters (estimated by the graphical impedence-match technique of Gault and Heitowit [1963] from the Hugoniots of ice, ice-saturated sand [Gaffney, 1979], and lead [van Thiel, 1966]) range from $\sim 5 \mathrm{kbar}$ in ice and $\sim 9 \mathrm{kbar}$ in ice-saturated sand for the slowest bullet $(V=0.33 \mathrm{~km} / \mathrm{s})$ to $\sim 40$ kbar in ice and $\sim 90 \mathrm{kbar}$ in ice-saturated sand for our fastest bullet $(V=1.5 \mathrm{~km} / \mathrm{s})$. Consequently, vaporization would only be expected in craters 8 and 10 in ice-saturated sand. Even for these craters, vaporization would be minimal and confined to ice near the impact point, because shock pressures decay rapidly with distance. Also, because the 50-kbar limit refers to liquid water, higher shock pressures would be required to vaporize ice, because extra energy is required to bring the temperature of the ice up to $0^{\circ} \mathrm{C}$ and then to melt the ice. The amount of melting at the low velocities of our projectiles is also very small [Cintala et al., 1979]. Thus we conclude that our targets act as dry, competent substances and that the large sizes of our craters are due to strength effects alone. At the higher impact velocities characteristic of cratering on Mars, melting and vaporization are expected to occur, but if ground temperatures at the impact site are far below freezing, the actual amount of water and vapor generated near 
the crater periphery that might produce wet crater enlargement may be negligible.

If the strong extrapolated dependence of $\sigma_{t}$ (ISS) on temperature is valid, then latitudinal variations in the subsurface temperature structure of the Martian crust of the type suggested by Fanale [1976] would give rise to latitudinal variations in the energy-diameter scaling relations as well. This would cause ice-saturated soil surfaces near the equator to appear older than similar surfaces near the poles. Johansen [1979], using the distribution of Martian impact crater ejecta blanket morphologies, has presented evidence favoring just such a substantial subsurface temperature variation: Martian rampart craters, which occur preferentially at low latitudes, have ejecta blanket morphologies that can be approximated by impacts into soupy mud [Gault and Greeley, 1978]. Other craters, which have ejecta blanket morphologies more like dry lunar craters, occur preferentially at high latitudes. If these ejecta morphologies are valid indicators of the amount of liquid groundwater present at the crater locality at the time of impact, then any enlargement that did occur in craters with diameters of a few kilometers or less may be attributed to the wet mechanisms in equatorial areas and to our dry, lowstrength mechanism in the colder polar regions. Alternatively, the lunarlike craters could be impacts which occurred in dry, rocky surfaces, in which case, rampart craters would be impacts in ground containing significant ice or water. If this were the case, then the dry, low-strength mechanism would probably not be significant because rampart crater ejecta morphologies would then imply significant melting at large distances from the impact point due to the passage of the shock, and any crater enlargement would be dominated by effects due to the melted water.

In conclusion, consideration of target strength broadens the already large uncertainty limits on current estimates of the absolute ages of Martian features. If some Martian surfaces were essentially ice-free during cratering, while others were saturated with ice or liquid water, strength considerations could possibly alter the currently accepted sequence of geologic events between different regions on Mars and between Mars and other planets in the solar system. Because these low-velocity experiments suggest trends and scaling differences which might affect our interpretation of Martian and icy planet ages and crater forms, and because of the indications of crater size dependence on material strength, we feel it highly desirable to extend cratering experiments and simultaneous material property measurements to lower temperatures, higher energies, and higher pressures and strain rates in order to provide a proper foundation for studying craters on Mars and beyond.

Acknowledgments. We thank Henry Moore and Joseph Boyce for critical reviews and Eloise Luera and Gayle Croft for assistance in preparation of the manuscript. We are also grateful to G. Hager, 31 st Naval Construction Regiment, for permission to use the Sea Bee C Rifle Range at Port Hueneme, California, to perform these experiments, and to David F. Wismen for courteous and helpful assistance in logistics at the rifle range. This work was partially supported by NASA grants NGL 05-007-002, NSG 7052 (University of California, Los Angeles) and NGL 05-002-105 (California Institute of Technology). Contribution 3292, Division of Geological and Planetary Sciences, California Institute of Technology, Pasadena, California 91125.

\section{REFERENCES}

Albertson, M. L., J. R. Barton, and D. B. Simons, Fluid Mechanics for Engineers, pp. 231-247, Prentice-Hall, Englewood Cliffs, N.J., 1960.
Bauer, A., and P. N. Calder, Projectile penetration in rock, in Proc. Can. Rock Mech. Symp. 5th, 157-170, 1969.

Boyce, J. M., and D. J. Roddy, Martian rampart craters: Crater processes that may affect diameter-frequency distributions (abstract), Reports of Planetary Geology Program, 1977-1978, NASA Tech. Memo., TM-79729, 162-165, 1978.

Burton, D. E., C. M. Snell, and J. B. Bryan, Computer design of high explosive experiments to simulate subsurface nuclear detonations, Nucl. Technol., 26, 65-87, 1975.

Butkovich, T. R., Mechanical properties of ice, Quart. Colo. Sch. Mines, 54, 349-360, 1959.

Butkovich, T. R. Influence of water and rocks on effects of underground nuclear explosions, J. Geophys Res., 76, 1993-2011, 1971.

Chapman, C. R., J. A. Mosher, and G. Simmons, Lunar cratering and erosion from Orbiter 5 photographs, $J$. Geophys. Res., 75, 1445$1466,1970$.

Cintala, M. J., E. M. Parmentier, and J. W. Head, Characteristics of cratering processes on icy bodies: Implications for outer planet satellites, Reports of the Planetary Geology Program, NASA Tech. Memo., TM-80339, 179-181, 1979.

Cohn, S. N., and T. J. Ahrens, Dynamic tensile strength of analogs to lunar rocks (abstract), in Lunar and Planetary Science X, pp. 224226, Lunar and Planetary Science Institute, Houston, Tex., 1979.

Cooper, H. F., Jr., A summary of explosion cratering phenomena relevant to meteor impact events, in Impact and Explosion Cratering, edited by D. J. Roddy, R. O. Pepin, and R. B. Merrill, pp. 1144, Pergamon, New York, 1977.

Culp, F. L., and H. L. Hooper, Study of impact cratering in sand, $J$. Appl. Phys., 32, 2480-2484, 1961.

Curran, D. R., D. A. Shockey, L. Seaman, and M. Austin, Mechanics and models of cratering in earth media, in Impact and Explosion Cratering, edited by D. J. Roddy, R. O. Pepin, and R. B. Merrill, pp. 1057-1087, Pergamon, New York, 1977.

Dence, M. R., R. A. F. Grieve, and P. B. Robertson, Terrestrial impact structures: Principal characteristics and energy considerations, in Impact and Explosion Cratering, edited by D. J. Roddy, R. O. Pepin and R. B. Merrill, pp. 247-275, Pergamon, New York, 1977.

Fanale, F. P., Martian volatiles: Their degassing history and geochemical fate, Icarus 28, 179-202, 1976.

Gaffney, E. S., Equation of state of ice and frozen soils (abstract), in Lunar and Planetary Science $X$, pp. 416-418, Lunar and Planetary Science Institute, Houston, Tex., 1979.

Gault, D. E., Saturation and equilibrium conditions for impact cratering on the lunar surface: Criteria \& implications, Radio Sci., 5, 273291, 1970.

Gault, D. E., Displaced mass, depth, diameter, and effects of oblique trajectories for impact craters formed in dense crystalline rocks, Moon, 6, 32-44, 1973.

Gault, D. E., Impact cratering, A Primer in Lunar Geology, NASA Tech. Memo., TM-62395, 137-173, 1974.

Gault, D. E., and R. Greeley, Exploratory experiments of impact craters formed in viscous-liquid targets: Analogs for Martian rampart craters?, Icarus, 34, 486-495, 1978.

Gault, D. E., and E. D. Heitowit, The partition of energy for hypervelocity impact craters formed in rock, Proc. Symp. Hypervelocity Impact 6th, 2(2), 419-456, 1963.

Gault, D. E., J. E. Guest, J. B. Murray, D. Dzurisin, and M. C. Malin, Some comparisons of impact craters on Mercury and the moon, $J$. Geophys. Res., 80, 2444-2460, 1975.

Gehring, J. W., Jr., Theory of impact on thin targets and shields and correlation with experiment, in High Velocity Impact Phenomena, edited by R. Kinslow, p. 105, Academic, New York, 1970a.

Gehring, J. W., Jr., Engineering considerations in hypervelocity impact, in High Velocity Impact Phenomena, edited by R. Kinslow, p. 463, Academic, New York, $1970 b$.

Hartmann, W. K., Terrestrial, lunar and interplanetary rock fragmentation, Icarus, 10, 201-213, 1969.

Hartmann, W. K., Relative crater production rates on planets, Icarus, $31,260-276,1977$

Hartung, J. B., F. Hörz, F. K. Aitken, D. E. Gault, and D. E. Brownlee, The development of microcrater populations on lunar rocks, Proc. Lunar Sci. Conf. 4th, 3213-3234, 1973.

Johansen, L. A., The latitude dependence of Martian splosh cratering and its relationship to water, Reports of Planetary Geology Program, NASA Tech. Memo., TM-80339, 123-125, 1979.

Kutter, H. K., and C. Fairhurst, On the fracture process in blasting, Int. J. Rock Mech. Mining Sci., 8, 181-202, 1971. 
LaLonde, W. S. Jr., and M. F. Janes, Concrete Engineering Handbook, pp. 1-46, McGraw-Hill, New York, 1961.

Masursky, H., J. M., Boyce, A. L. Dial, G. G. Schaber, and M. E Strobell, Classification and time of formation of Martian channels based on Viking data, J. Geophys. Res., 82, 4016-4038, 1977.

Maurer, W. C., and J. S. Rinehart, Impact crater formation in rock, $J$. Appl. Phys., 31, 1247-1252, 1960.

Moore, H. J., Missile impact craters (White Sands Missile Range, NM) and applications to lunar research, U.S. Geol. Surv. Prof. Pap., 812-B, 47 pp., 1976.

Moore, H. J., R. V. Lugn, and D. E. Gault, Experimental hypervelocity impact craters in rock, Proc. Hypervelocity Impact Symp. $5 t h, I(2), 625-643,1962$.

Neukum G., and B. König, Dating of individual lunar craters, Proc. Lunar Sci. Conf. 7th, 2876-2881, 1976.

Oberbeck, V. R., Laboratory simulation of impact cratering with high explosives, NASA Tech. Memo., TM X-62010, 56 pp., 1970.

Oberbeck, V. R., Laboratory simulation of impact cratering with high explosives, J. Geophys. Res., 76, 5732-5749, 1971.

Ostro, S. J., and G. H. Pettengill, Icy craters on the Galilean satellites?, Icarus, 34, 268-279, 1978.

Quaide, W. L., and V. R. Oberbeck, Thickness determinations of the lunar surface layer from lunar impact craters, J. Geophys Res., 73, 5247-5270, 1968.

Reichmuth, D. R., Point load testing of brittle materials to determine tensile strength and relative brittleness, in Status of Practical Rock Mechanics, edited by N. E. Grosvenor and B. W. Paulding, Jr., pp. 134-159, American Institute of Mining, Metallurgy, and Petrology Engineering, New York, 1968.

Rinehart, J. S., Dynamic fracture strengths of rocks, Proc. Rock Mech. Symp. 7th, 205-208, 1965.

Schneider, P. J. Conduction Heat Transfer, pp. 263-267, AddisonWesley, Reading, Mass., 1974.
Schultz, P. H., R. Greeley, and D. E. Gault, Interpreting statistics of small lunar craters, Proc. Lunar Sci. Conf. 8th, 3539-3564, 1977.

Schultz, P. H., and J. Spencer, Effects of substrate strength on crater statistics: Implications for surface ages and gravity scaling (abstract), in Lunar and Planetary Science $X$, pp. 1081-1083, Lunar and Planetary Science Institute, Houston, Tex., 1979.

Stöffler, D., D. E. Gault, J. Wedekind, and G. Polkowski, Experimental hypervelocity impact into quartz sand: Distribution and shock metamorphism of ejecta, J. Geophys. Res., 80, 4062-4077, 1975.

Toman, J., Results of cratering experiments, in Peaceful Nuclear Explosions, pp. 345-375, International Atomic Energy Agency, Vienna, Austria, 1970.

Tsytovich, N. A., The Mechanics of Frozen Ground, 426 pp., Scripta Book Co., Washington, D. C., 1975.

van Thiel, M. (Ed.), Compendium of shock wave data, Rep. UCRL50108, vol. 1, sects. A-1 and A-2, Lawrence Radiat. Lab., Livermore, Calif., 1966.

Vanzant, B. W., Dynamic rock penetration tests at atmospheric pressure, in Rock Mechanics: Proceedings of the 5th Symposium on Rock Mechanics, edited by C. Fairhurst, pp. 61-91, Pergamon, New York, 1963.

Vortman, L. J., Craters from surface explosions and scaling laws, $J$. Geophys. Res., 73, 4621-4636, 1968.

Wijk, G., G. Rehbinder, and G. Lögdström, The relation between the uniaxial tensile strength and the sample size for Bohus granite, Rock Mech., 10, 201-219, 1978.

Young, R. A., Mare crater size-frequency distributions: Implications for relative surface ages and regolith development, Proc. Lunar Sci. Conf. 6th, 2645-2662, 1975.

(Received April 2, 1979;

revised July 19, 1979;

accepted August 31, 1979.) 